\title{
Entanglements and entrapment on the pathway towards domestication
}

\author{
By Dorian Q Fuller ${ }^{1}$, Chris Stevens ${ }^{1}$, Leilani Lucas ${ }^{1}$, Charlene Murphy ${ }^{1}$, and Ling Qin ${ }^{2}$ \\ 1. Institute of Archaeology, University College London \\ 2. School of Archaeology and Museology, Peking University
}

\section{Introduction}

The domestication of wild species that sustained hunter-gatherers, as happened with cereals, is a prime example of cultural and ecological entanglement. As humans relied more on a narrower range of species for calories, the changes associated with their processing required them to engage in different behavioral patterns. In turn, the species themselves evolved characteristics, i.e. domestication traits, which further transformed human behavior. Eventually these changes made the plants reliant on human management and propagation for reproduction and likewise humans became more dependent on plants to maintain subsistence and cultural trajectories.

The notion of domestication pathways as entanglement has recently gained ground as the complex mesh of interrelationships involved has become increasingly evident (e.g. Fuller et al. 2010; 2012; Barton and Denham 2011; Hodder 2012). In this contribution we explore different domestication pathways for four main regions, placing instances of crop domestication within their ecological and cultural contexts: (1) sedentary cereal cultivators of the Levant, (2) wetland rice cultivators of the Yangtze Basin, (3) millet cultivators of the North-East Asian steppe, (4) milletpulse cultivation and pastoralism in the Southern India savannah.

These contrasting case studies provide a means by which each entanglement, comprising varying ecologies, aspects of plant physiology, and cultural traditions resulted in differing domestication pathways. While there are many commonalities to domestication in how plants adapted to cultural landscapes, these cases reveal important differences between the four regions that are a product of variations in lifestyles, and their distinct cultural histories.

Within the last decade, evidence for morphological changes of domestication supports a protracted process (Fuller et al. 2012; 2013; Tanno and Willcox 2012), particularly in the case of the Near East, the most widely-studied region for agricultural origins. Additionally, there has been a growing recognition that the anthropogenic ecology of early agriculture created new plant communities, or weed floras (Willcox 2012). These lines of complementary evidence allow us to deduce early cultivation behaviors, and the resulting changes from those behaviors, thus unravelling the complex feedback between human action and evolutionary change in crops and associated arable weeds (Fuller et al. 2010).

The expansion of archaeobotanical research in other regions, such as China, India and subSaharan Africa has allowed parallel pathways to domestication to be studied (Fuller and Allaby 2009; Manning et al. 2011) forcing some reconsideration of the universality of Near Eastern processes, often taken to represent the origins of agriculture on a global level. Evidence from these additional three areas provides informative contrasts between each other and the Near East. The aim of this paper is to sketch these alternative agricultural pathways and consider how the entanglements of plant species characteristics and pre-existing hunter-gatherer lifeway's conditioned different pathways of subsistence change that ultimately converged on what we recognize as agriculture. 


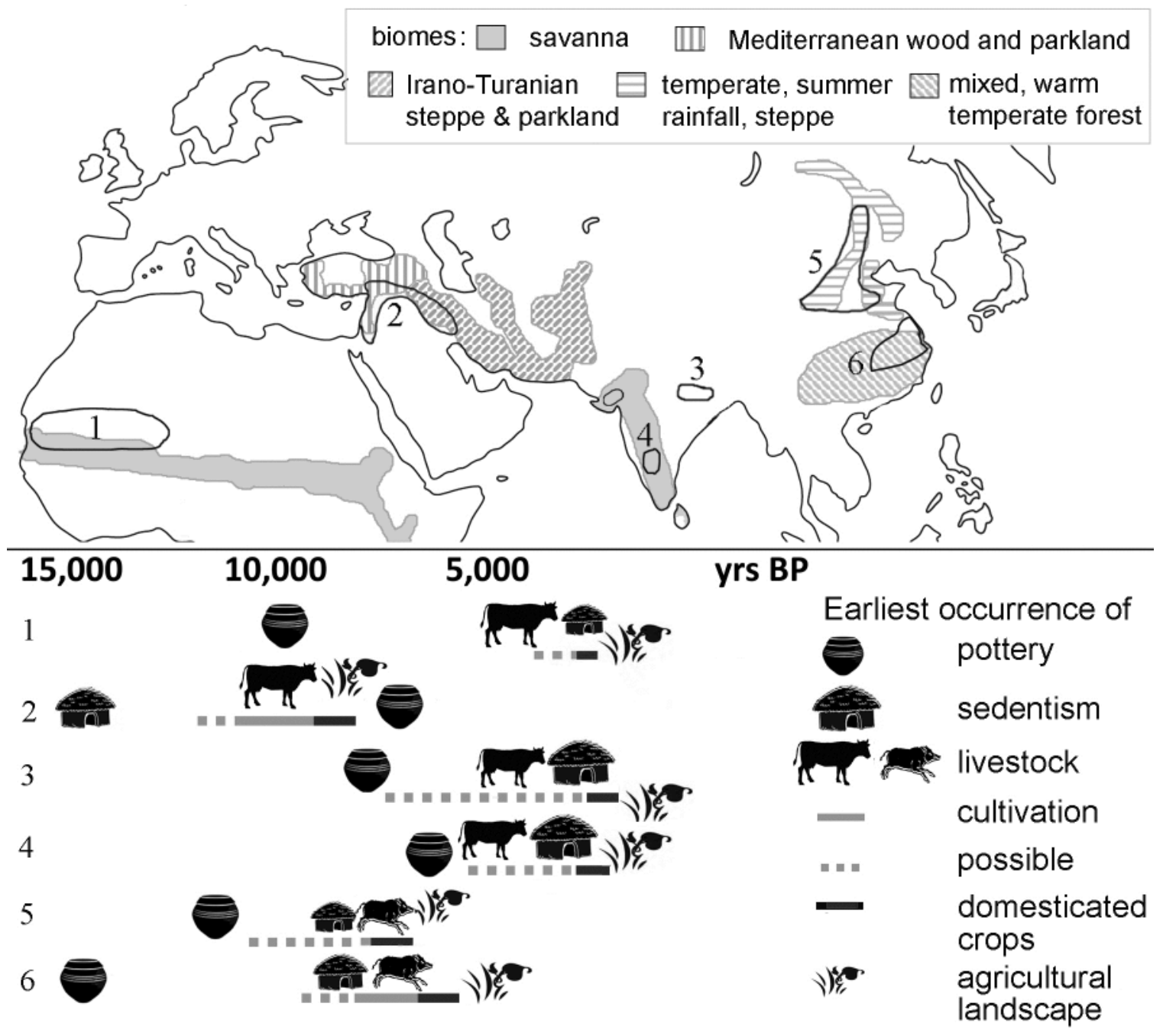

Figure 1:Map and schematic timelines for the emergence of Neolithic agricultural elements in selected Old World regions, in relation to selected vegetational zones. For the cases of Gangetic India and western Africa, not discussed in the present paper, see Fuller 2011 and Manning et al. 2011.

At a global level, the long-term impact of agricultural origins has been sedentism, population increase, increased reliance on a more limited range of domesticated food stuffs, and a diversification of material technologies, including ceramics, whichin all but one region,the Near East,preceded domestication.Despite many aspects of convergence in the broadest sense by which various regions domesticated plants, the timing of the domestication of animals, ceramics and villages, and the sequence and timing by which this "Neolithisation" occurred appears to have varied greatly (Figure 1).

As a basis for comparison, we sketch our current understanding of five key aspects of the domestication entanglement using the presumed prototype, the Near East, for comparison. First, we consider the environmental context of the wild progenitors of the following crops: wheat and barley in the Fertile Crescent; East Asian rice and millets; and the pulses and millet of South India. We discuss how these species would have been incorporated into foraging practices in terms of spatial and seasonal availability, and how cultivation may have created new opportunities and costs in terms of other resources. Second, we consider the creation of fields including clearance activities. Third, we consider the gathering and processing of crops from harvesting through dehusking and winnowing to storage. Fourth, we consider how site occupation, seasonal versus sedentary, appears to relate to foraging, and early cultivation and how convergent trends towards full sedentism are seen with the transition to full domestication. Fifth, we consider traditions of food preparation and cooking and how the selections of crops, wild foods and development of technologies followed 
differing trajectories with or after the advent of cultivation. Under this heading we consider the practices of grinding, oven baking and the use of ceramics. Ultimately, by the end of the Neolithic, ceramics were technologies used everywhere, but the nature of ceramic form and function and their centrality to food preparation systems differed markedly with geographic region and the crops processed and consumed (Fuller and Rowlands 2011).

\section{Elements of entanglement on the pathway to domestication for the sedentary cereal cultivators of the Levant}

Within the inter-relationships that form the domestication entanglement, we can group the "things" that humans are dependent on (sensu Hodder 2012), and in turn are dependent on humans, under three categories: (1) plant physiology/morphology, (2) human behavior, and (3) resource environment.

The wild progenitors of the Near Eastern crops are generally well known and well understood in comparison to some of the other regions (Zohary et al. 2012). These wild cereals, wheats and barley, were generally distributed over the drier oak parkland steppe, lying between the Mediterranean woodland zone and the open-grassland steppe. The wild progenitors of the legumes, lentil, pea, chickpea, and vetches, were also distributed within this general area in woodland clearings and margins.

Within plant physiology we find a number of factors that may be affected by human interaction, via conscious or unconscious selection (see Zohary 1969; Harlan et al. 1973; Fuller and Allaby 2009). Particularly significant are changes to plant reproduction cycles and therefore the survival of future generations (Figure 2). These include loss of dispersal mechanisms, e.g. awns (Elbaum et al. 2007; Fuller and Allaby 2009); changes in growth habit, e.g. the degree of sidebranching (see Doust 2007); and the size (Fuller et al. 2013)and number of the seeds (Zohary et al. 2012). Of greater significance are changes resulting in the loss of dormancy in seeds (Fuller and Allaby 2009), causing seeds to germinate straight after seed-setting rather than forming a persistent seed bank; the loss of shattering, in which seeds remain on the plant in the ear rather than falling to the ground (Fuller and Allaby 2009; Fuller et al. 2013); and finally the synchronous ripening of grains upon the ear (Fuller 2007). Further, research has shown that many of these changes may be genetically tied, for example, seed dormancy, shattering and color are all interrelated in rice (Gu et al. 2005). Therefore, conscious or unconscious selection by humans for one trait may inadvertently bring about changes within other traits, although such genetic linkage is still under-researched across most crops.

As an archaeologically detectable trait, the increase in seed size as a result of human-plant interaction provides a good scenario for the exploration of entanglements. This is documented across a wide number of species, including cereals, pulses, and oilseeds (Fuller et al. 2013). The act of bringing wild-type plants into the cultivated environment, in which soil is cleared and loosenedfor sowing lead to an unintended evolutionary trend for greater seed size (see Harlan et al. 1973; Fuller et al. 2010). There is experimental evidence for some species that depth of greater seed burial may select for this change (Kluyver et al. 2013), although other aspects of the new soil conditions of cultivation were also probably important. On the most basic level larger seeds provide more energy reserves and hence provide a competitive advantage to larger seeded plants in terms of establishing themselves in the field (Moles et al. 2007). As with all traits, there appears to be an optimum size over which this competitive advantage is lost (indeed some studies indicate that germination rates eventually fall with larger seed size). As such investigations into changes in seed size for domesticates over time show a leveling off to occur, more or less concomitant, with full domestication (Fuller et al. 2013).

In as much as these changes are brought about by human behaviors so in turn, over time, did these changes come to modify human behavior on the pathway from collection, to cultivation to domestication. First, the increase of grain size brought about gains in yield per harvest, making these increasing better than wild stands of the same of species.Other human adjustments include those affecting material culture and technology, for example,the development of tools, ceramics and 
structures,to modify the growing environment, for harvesting, storage, processing, and finally to grind, cook and consume the grain. In the Near East grinding tools have a deep history with the earliest evidence dated to the later Palaeolithic, but with a marked increase in quernstones for flour preparation correlated with the PPNA and the first clear evidence for plant cultivation(Wright 1994; Fuller and Rowlands 2011). Sickles that would enhance harvesting predate this period, although some have questioned whether these were developed specifically for wild cereals (Sherratt 1997:274; Fuller 2007), rather than, for example, basketry, it is nevertheless clear that these came to be for cereal harvests in later occupations.

\section{Core Domestication Syndrome Entanglements (shared)}

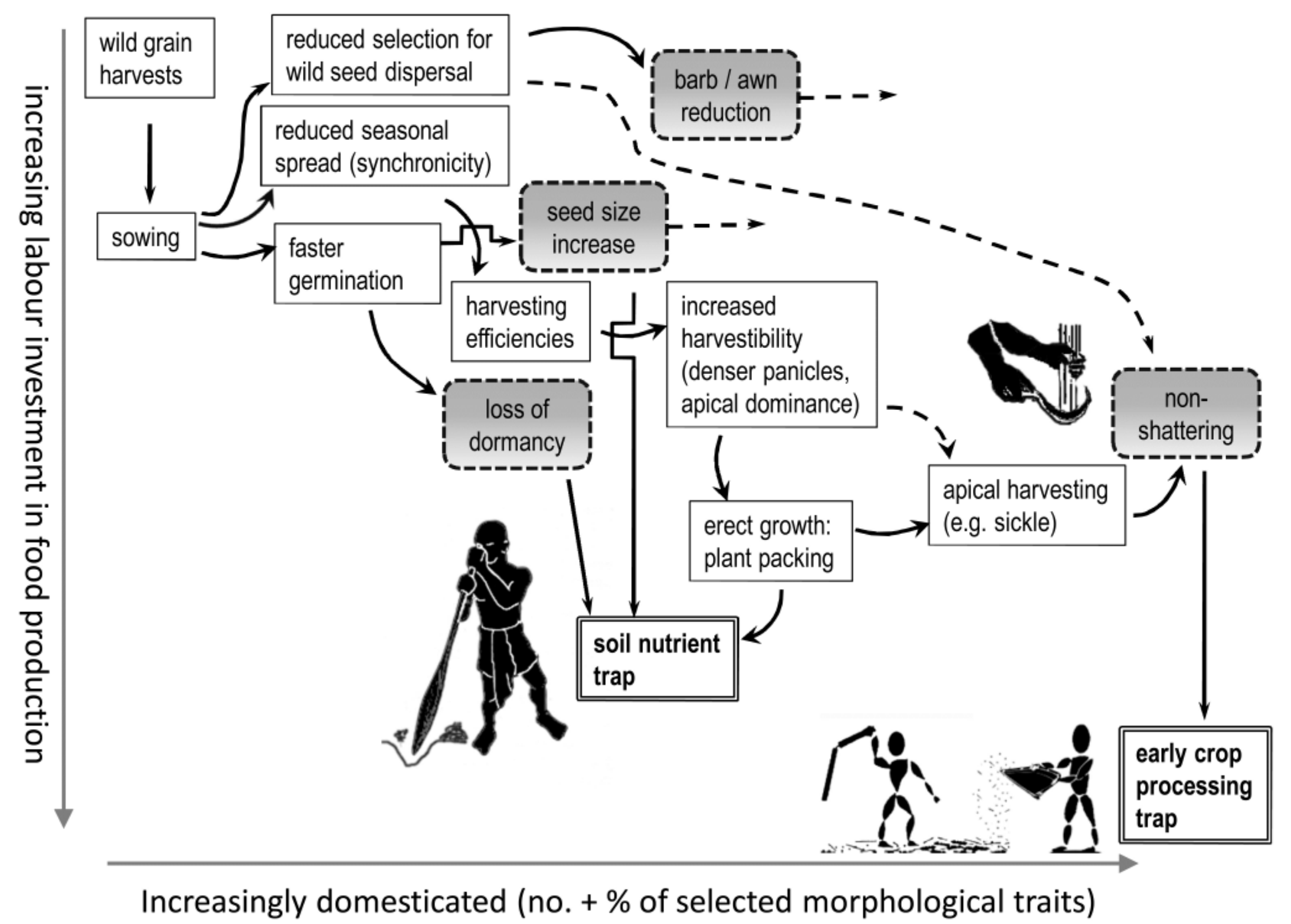

Figure 2: Core domestication syndrome entanglements (shared across regions and cereal taxa)

These actions then modified the scheduling of labor which in turn transformed social relationships embedded within the production and consumption of the Levantine cereals. A major example is that the processing sequence inevitably underwent changes with the evolution of nonshattering forms. This fundamental transformation would have created labor demands for threshing activities to break apart the ear, an activity unknown to peoples exploiting naturally-shattering wild populations (Figure 2). However, non-shattering forms would have assured greater yields per harvest (Fuller et al. 2010; Hodder 2012:76) shifting the collection of cereals to later in the year and allowing the synchronized harvest of fully ripened stands.

We also must consider the soil environment. It is modified through clearance, effectively removing other plants competing with the cereals, and through tillage in which the soil is aerated and prepared (see Fuller 2007). In turn, the act of removing vegetation can result in the depletion of soil nutrients leading to further modification of human behavior through the need to manure. Recent inferences about early Near Eastern agriculture and its Neolithic European derivatives suggest 
smaller scale cultivation with intensive maintenance of soil fertility (Bogaard et al. 2013). This indicates further labor traps of the increasingly productive cultivation. These labor traps, as well as increased yields to store, contribute to reduced mobility, in which humans become tied to fields, threshing floors, cereal stores, and the house.

So, the aspects of human behavior that create the shift from gathering of wild cereals to planting and harvesting became increasingly limited in space and in time. Hunter-gatherers might move through the landscape over a protracted time period harvesting from wild stands as they ripen (Zohary 1969:57) in a system that was time effective. By contrast, the domestication entanglement sees humans trapped into harvesting cereals from a single set of fields (space-limited) in a time period perhaps covering a limited window. Further, the limited space means that harvesting is likely to have moved toward increasing efficacy of return from each unit of land, through either multiple harvests or new techniques, such as sickles (Fuller 2007). Thus, the space-limited and timeconstrained nature of cultivation forced a growing importance on permanent storage.

Plants compete with each other on many levels. In particular, given that many wild progenitors of crop species do not ripen synchronously and have seed dormancy, we can deduce that natural selection pressures favor plants that spread their seed over protracted time-periods. The act of repeated annual clearance, followed by the sowing of seed, creates a level playing field in which there is a clear competitive advantage to those plants that are able to get their seeds into the next seedcorn to be sown. Thus, seeds without dormancy mechanisms, capable of germinating straight away are favored as are larger more efficient sprouting seeds. These larger seeds should more effectively compete with each other, and other species, for space and sunlight or in emerging from depth. It also favors ripening of seeds when the majority of other plants are ripening, so as to be concentrated in the same harvest.

Changes in processing may also be seen in terms of space-limited returns. The grinding of grain favors increased edible calories from the same amount of grain, and hence the amount of harvested land, or the same amount of time cultivating. This efficiency in returns from land, however, does come with the cost of food preparation, but is likely to have been reinforced by adesire for more food, not just to feed more people but to support more seasonal, social gathering and feasting, among the seasonally and spatially concentrated cultivation populations (Asouti and Fuller 2013). Growing taste for the kinds of food produced, such as breads, would have also reinforced the agricultural and processing labor.

\section{Plant domestication by wetland collectors: the case of East and South Asian rice}

The wild progenitor of East Asian rice (Oryza rufipogon), is a wetland perennial which makes it distinct from crops of other regions that were frequently annual species. The perennial ancestor of early East Asian rice (Oryza sativa subsp. japonica) differed from the annual ancestor (Oryza nivara) of the early cultivars of India (Oryza sativa subsp. indica) (Fuller and Qin 2009; Fuller et al. 2010). The archaeological consensus is that in the Yangtze basin, broadly speaking the Middle or Lower Yangtze, possibly including northern tributaries, the ancestors of japonica rice was domesticated in the early to middle Holocene (Fuller et al. 2010; Cohen 2011; Qin 2012).

Ethnographic work in North America suggests how wild rice may have been used as a stable component of hunter and gathering economies in general. The staple of the Ojibwa people was American wild annual rice (Zizania aquatica), similar ecologically and a taxonomic cousin of East Asian rice, although as an annual it was more uniformly a high grain-producer. Of particular relevance is the recording of the binding of individual rice panicles (the inflorescence or ear) to prevent grain loss (Danziger 1979; Doolittle 2000). The slow ripening of the panicle provided the potential for two to three harvests a year (cf. Vennum 1988), and the Ojibwa harvested the rice by knocking the heads (Danziger 1979), assumedly in order not to damage the plant prior to the next harvest. Similar binding practices have also been reported from tribes in eastern India who gather wild rice (Oryza rufiopogon/nivara) as a supplement to their agricultural diets (e.g. Vaughan et al. 2008).

One of the many early genetic mutations in rice that differentiates domesticated Oryza 
sativa from its wild progenitors, is the transition to a more tightly growing panicle (Ishii et al. 2013). In early wild-type populations this tighter form would have led to spikelets becoming entangled in the panicle branching when they separated from the rachis, making the harvest of wild grains more efficient, perhaps yielding 50\% more grains per effort (Ishii et al. 2013). In essence this mutation would have reduced the need for practices, such as binding.

A key implication of poor grain production in wild perennial rice species is the use of drought stress to increase seed productivity (Fuller and Qin 2009). Initially these could have simply been about clearing the shallow and seasonally dry margins of natural wetlands, and sowing early wild rice crops there. However, later it may have become necessary to extend these drying wetland margins artificially perhaps leading to experiments which increased grain production by simulating drought stress. Excavation of some of the earliest preserved field-systems, dating to ca. $4000 \mathrm{BC}$ (Late Majiabang period) supports these theories and clearly shows that they were well-suited for control of water-flow. Such systems comprise small dugout fields, just a few meters across, connected by channels and linked to deeper pits for water drainage (Fuller and Qin 2009). These small field systems were ideal for closely managing water, and potentially could be drained prior to flowering to bring out the drought response for higher grain production. The natural growth habit of wild rice is loose and spreading and has the advantage under wild conditions of colonizing more soil space, resulting in greater access to soil nutrients and soil water. However, such growth habits are ill-suited to these small field units for effective growing conditions or indeed production. Thus, the evolution of dense, erect-growth habit much have been selected under earlier cultivation (before $4000 \mathrm{BC}$ ) to allow these small fields to be effective.

Higher grain production, would have depleted the soil of nutrients; however, these small field units would have been relatively manageable in terms of artificial input of fertilizing material. In the absence of herds of dung-producing ungulates, archaeological evidence points to the utilization of settlement midden material within manuring practices. Such behavioral practices can account for the quantities of typical midden components, comprising charred plant remains and ceramic sherds recovered from these early paddy soils. The need to add nutrients to the soil, can be called the "soil nutrient trap" (Fuller et al. 2010), as increased plant productivity entrapped people into adding nutrients into the soil.

The result of this entanglement of interrelationships between humans, rice and fields made rice more productive, but would reduce the time available for the gathering of wild plant foods, such as various utilized nuts (Fuller and Qin 2010). The availability of these nuts is generally within late summer to autumn, when demand for labor for managing both crop and fields would have been at its greatest. Further, the drive towards shallower, and more artificially shallow and drier locales for growing rice would have pushed the deeper habitats of the aquatic nuts further away and potentially reduced the area of their availability.

The archaeological evidence bears testament to how this domestication entanglement played out, and we see how an increasingly complex relationship with just a single crop led to a decline in the archaeobotanical record for wild foods, in particular acorns and water chestnuts (Fuller and Qin 2010). It should be noted that sickles or harvesting knives for harvesting whole panicles, in contrast to the Near East where they precede domestication, arrive within the Lower Yangtze relatively late, post-domestication, perhaps ca. 3300 BC (Fuller et al. 2008). As such it must be speculated that harvesting of rice during the domestication processes was probably through uprooting, with denser panicles leading to less seed loss within shattering wild type plants, but overtime favoring nonshattering forms. The emergence of non-shattering spikelets in larger proportions would have, in turn, entrapped people into threshing and into adjusting harvest practices. Thus, physiological changes within the plant itself resulted in humans becoming entrapped in additional labor (Figure 2 ), and developing subsequent technological innovations. The coincidence of the rice harvest season with that of wild forest resources has the consequence that further investment in rice, which had its own rewards of higher yields, pushed people towards abandoning many of their wild staples, like acorns and Trapa, wild chestnuts (Fuller and Qin 2010). The particular problem of perenniality in which wild rice was a poor producer meant that the necessary labor inputs during the domestication 
process represented a greater level of entrapment than was true of early annual cultivars, such as wheat, barley or millets (Figure 3).

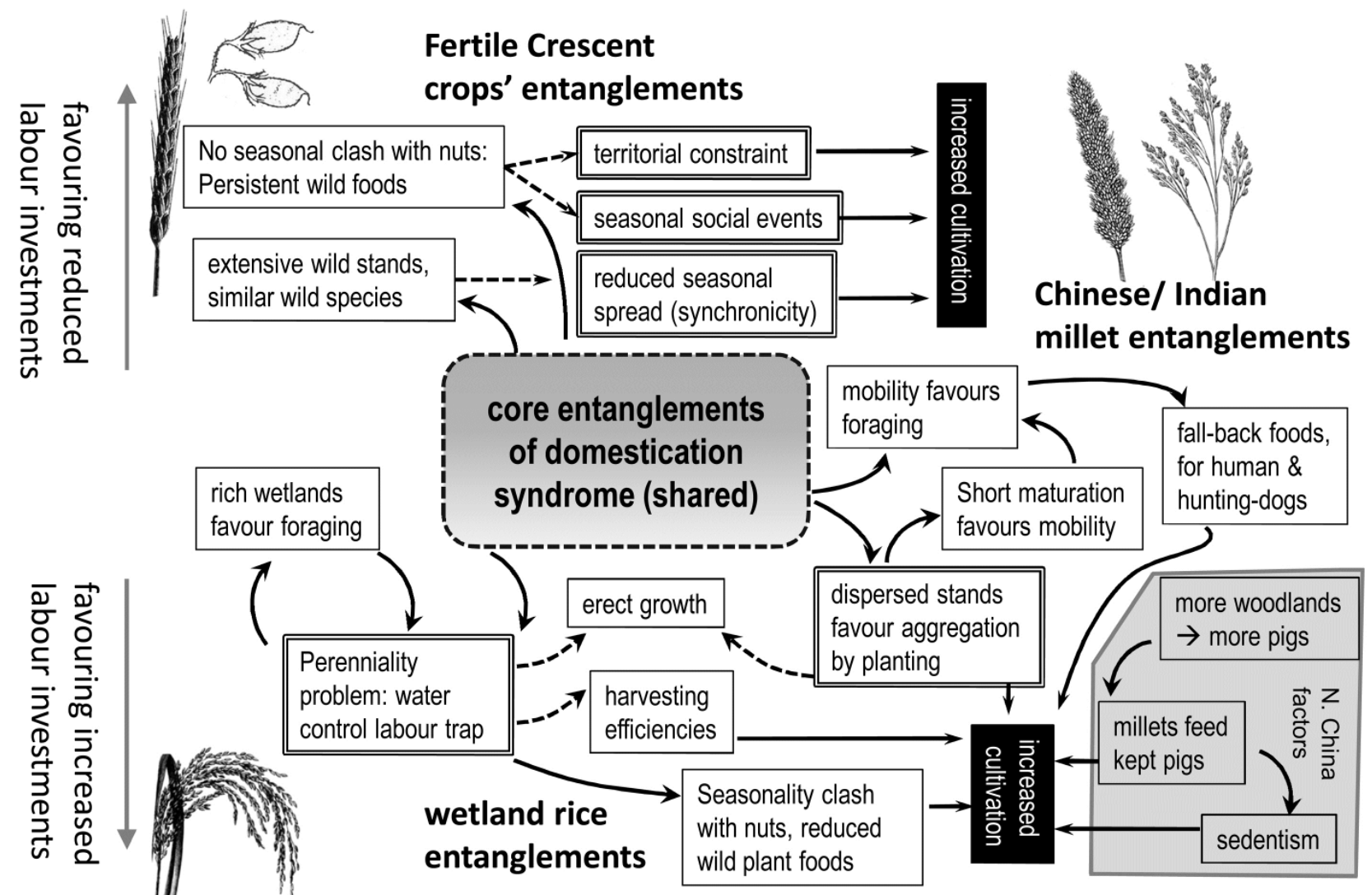

Figure 3: Expanded entanglegram with regionally specific factors.

\section{Plant domestication by mobile hunters: Chinese loess millets}

Northern China, the Yellow River Basin and hill ranges to its north, has long been recognized as an early center of agriculture founded on millets, which continued to serve the region as the main staple during the Early Bronze Age (Li 1970). The area sees the domestication of two millet species, foxtail millet (Setaria italica) and broomcorn millet (Panicum milaceum). The wild progenitor of foxtail millet is clear, with multiple origins suggested (Meiko et al. 2013), while for Panicum miliaceum the progenitor could be extinct, perhaps the weedy Panicum miliaceum subsp. ruderale (Hunt et al. 2011; De Wet 2000) While foxtail millet is highly drought tolerant, its wild forms tend to favor a range of environments (Douglas et al. 1995). Use of the wild progenitor could have been extensive and non-intensive as the period for flowering, ripening and shattering in a given stand may last for up to four months, during which time there would always be some spikelets ready to harvest ( $\mathrm{Lu}$ 2002). Certainly compared with most of the wild grasses of the eastern Eurasian steppe Panicum is relatively large-grained, and thus more grain could be had per unit of dehusking time than would have been true of many other grasses of the (on the grassland composition of northern China, see Wang 1961), which may account for a preference for this grass amongst early foragers in northern China and other regions. Nevertheless, what were probably dispersed patches of these wild millets would have suited exploitation by mobile hunters, but with cultivation of new artificial patches and storage, these would have become suitable seasonal foods, or foods of need, for both humans and their hunting dogs (Bettinger et al. 2010). With growing sedentism, millets also became suitable feed for kept pigs which would have reduced to need to rely on hunted deer for meat (see Figure 3).

The earliest evidence for the possible cultivation of millets is provided from a dispersed set of, most likely, sedentary cultures, all dating to about $6000 \mathrm{BC}$, and distributed along the southern and eastern margins of the loess plateau. Current research into the start of millet agriculture has 
focused on these cultures (e.g. Bettingeret al. 2010; Yang et al. 2013; Qin 2012), while claims for earlier precursors (8000-10,000 BC), based on starch grains and phytoliths, should be treated with caution given the difficulty in determining the identification of their domesticated or cultivated status. Foxtail millet underwent similar changes during domestication to those already discussed for other cereals (Figure 2), bringing about major changes in plant architecture. While there is a change from shattering to non-shattering, archaeologically evidence that might record this change has been elusive. Changes in shape and increased grain size have a much higher potential to be tracked archaeologically, although such studies are still needed. However, identification issues may be compounded by the presence of immature grains (Song et al. 2013).

Present archaeological evidence suggests that harvesting knives, which appear in the Middle Neolithic around 6000-5000 cal. BC in Northern China (Fuller et al. 2008), did not precede cultivation. However, given the eventual emergence of non-shattering forms, it seems probable that harvesting by cutting the plant is likely to have played a similar role to that hypothesized for wheat and barley. Likewise, we can speculate that this change saw the requirement within foxtail millet for threshing.

For broomtail millet the pattern is less clear. Ripening of the panicles of Panicum miliaceum is often uneven (Matz 1986) and as a consequence some shattering of the already ripe grain on the panicle occurs if harvested fully ripe. A commonly employed solution is to cut the crop while it is still green, then allowing it to ripen/dry prior to threshing (cf. Lyon and Baltensperger1995). Alternative strategies are to harvest through uprooting or through stripping the seed from the stalk using wooden combs (Bakels 2009:118). It might be noted that ethnographic work on wild Panicum in Australia also records harvesting through stripping the grain, or uprooting the plant somewhat green (Nesbitt 2005).

As with many cereals, domestication saw the loss of seed dormancy. Dormancy within wild Panicum and Setaria species is broken by chilling followed by higher temperatures, e.g. $25-30^{\circ} \mathrm{C}$ (Baskin and Baskin 2001:378-379), and as with many seeds there is also a light requirement. Given the colder winter conditions of northern China, such short-term dormancy, would promote germination in May to June when temperatures were higher and rainfall is at its peak, with plants over-wintering during the cold-dry season as seed. Both wild and cultivated foxtail millet can reach maturity from germination in around four months in late summer/early autumn, although seed setting lasts somewhat longer.

Appraising the moment when the loss of dormancy occurred during domestication provides interesting food for thought. Wild type grains, requiring chilling, could be sown (naturally or deliberately) in autumn/winter; however, loss of seed through natural predation would mean that larger quantities of grain would need to be sown. Further, such practices would not lead the loss of the dormancy mechanisms seen in domesticated varieties, while conversely seeds lacking dormancy mechanisms are unlikely to have survived to produce viable offspring (cf. Colosiet al. 1988). As such the loss of dormancy during domestication could only occur if accompanied by the sowing of the grain within spring to summer. Thus, once dormancy was lost humans would become locked into this sowing regime.

It has been proposed that underground pits, as evidenced at Cishan (8000-5500 BC), for example, were used for millet storage (Lu et al. 2009; Bettingeret al. 2010). It might be noted that pit storage is often dependent on germination of grain around the edge of a sealed pit in order to use the remaining oxygen to seal it, preventing both insect pests and the growth of mold (see Reynolds 1974). As such, it is questionable whether people could have developed such grain storage practices until grains had lost their dormancy.

\section{Plant domestication via shifting cultivation: re-examining the South Deccan, India}

Peninsular India, the Deccan, has only recently entered our awareness as a possible centre of agricultural origins (Fuller 2011). Recent archaeobotany has revealed that the staple crops of the Neolithic of this region were native domesticates, including horsegram (Macrotyloma uniflorum), mungbean (Vigna radiata), and browntop millet (Brachiaria ramosa). Admittedly, the Neolithic 
here is late (from ca. $3000 \mathrm{BC}$ ), and faunal resources are dominated by introduced pastoral herds, of cattle, sheep and goats. Thus, an earlier dispersal of mobile pastoral-collectors may precede the development of agricultural economies with plant cultivation and later tendencies towards sedentism. Nevertheless, plant cultivation appears to have been independent, in the sense that locally wild species were brought into cultivation and domesticated rather than developing from introduced crops first (Fuller 2011).

These wild progenitors span both the tropical wet to dry deciduous forests on the hills of the Deccan margins and the drier savannah woodland zones of the central peninsula (Fuller 2011:S248). This is like the more Mediterranean habitat of wild pulses in the Near East and the drier steppic habitat of wild barley and wheat, in combining plant cultivars from across adjacent habitats that must have been frequented by earlier mobile collectors. These native species did not form extensive stands as wild wheats, barley, or wild rice do, but rather were likely found in local dense patches in favourable microenvironments. This suited exploitation by transhumant groups, much as was the case for wild Chinese millets. Then again, increased availability would have been possible through aggregating stands, setting in motion the selection of core domestication entanglements (Figures 2, $3)$.

The mid-Holocene pastoralists of this region, like the Mesolithic hunter-gatherers that would have already lived here, must have had a seasonally transhumant pattern, tied to the flow and ebb of summer monsoon rains. Dry seasons, focused on March to May, would have forced herd-following hunters or herders to concentrate on the few perennial water resources, and some of these sites became major foci of pastoralist events that were marked on the landscape by large dung-burning events that left their mark as the ashmounds of south India (Boivin 2004; Fuller et al.2001; Johansen 2004). The rainy summers encouraged band dispersal, and would have been the season suited to early cultivation, producing post-monsoon harvests that could be the focus on social gathering, and growing fixed communities, that eventually became sedentary. This could be seen to fit a "scheduled availability" model (Marshall and Hildebrand 2002; Fuller 2011) of valued foods within a round of annual mobility.

Despite the common sowing period for these native species, there was likely two harvest periods, one for the beans and an earlier one for millets. Millets were likely harvested somewhat green, and perhaps required multiple harvestings. Thus, taken together the early crops required a protracted period of harvesting over perhaps two months, reducing the potential to exploit other plant resources and tying cultivators to these resources and sites near the planted stands. In these pulses, size increase was not part of the initial domestication syndrome and seed size increase was likely due to changes in agricultural techniques, such as deeper tillage using ards (Fuller and Harvey 2006:257; Fuller 2007:903, 915-916).

In terms of processing, a common approach in South India to pulse preparation is to dry roast them and then grind them into flour, or to prepare flours which are then soaked and fermented. Such flours are mixed with cereal (millet, in modern times more often rice) flours to prepare batters that become steamed, boiled or fried for stiff porridge (uppam), flatbread (various roti, papads), pancakes (dosa) or dumplings (idli, vadai). The high frequency of pulse recovery compared to the Indus region or Mediterranean, was suggested to indicate the likely importance of pulse dryroasting and flours in prehistoric South India (Fuller and Harvey 2006; Fuller and Rowlands 2011). Ceramics for the early Southern Neolithic include a range of bulbous pots that could be used for boiling and large open bowls that suggest communal consumption of served foods, rather than individual servings (Boivin et al.2005). Subsequent innovations included perforated bottom vessels. The latter might mean that steaming developed, a common traditional cooking technique for combined batters of pulse and cereal (millet or rice) flour, such as in the production of south Indian idli (Kimata and Sakamoto 1992). Thus, over the course of the Neolithic as sedentism became established and some social differentiation developed, cooking and serving repertoires diversified as did the range of crops. By contrast, at the start of the Neolithic ceramics point towards simple single pot meals and the need for a small number of serving dishes, making ceramic use more compatible with a seasonally transhumant lifestyle, or pastoralist-gatherer turned seasonal cultivator. 


\section{Discussion: fixed and variable path dependencies in plant domestication}

The transition to agriculture is arguably one of the most decisive periods of human cultural history. A period which sees the relationship between humans and their food sources undergo changes that echo through to the present, in which new entanglements took form and a series of dependencies between plants and humans began to take shape. Similarities in basic physical and genetic structure of cereals have undoubtedly led to similarities in the way in which humans interacted with them. The affordances offered by cereal plants to human beings wishing to exploit them for food provide a limited number of interactions and the results of these interactions, such as the development of non-shattering and the requirement for threshing, within all four geographical regions suggests that once this pathway was first embarked upon that there inevitably comes a point of no return. Thus, the basic cereal domestication syndrome appears to represent a fairly rigid set of path dependencies and inevitable consequences (Figure 2), which probably accounts for the recurrence of domestication traits and similarities of evolutionary rates across centres of cereal domestication (Fuller et al. 2013). Through the requirement for increasing labor needed to tend soils, to harvest, and for threshing, people became locked into subsistence patterns that were reliant on a narrow range of crops. This reliance has its own social entanglements including the storage of surpluses, and the consumption of crops, including for feasting.

On the other hand, connections between humans and things also differed on the basis of the different regional environments of early cultivation. Each of the geographical areas reviewed had its own unique climate and flora, which afforded certain opportunities for the exploitation of wild plants. In the case of the Yangtze basin and the Near East, extensive wild cereal stands and other reliable resources, such as nuts, allows for sedentism; but, on its own, this can be suggested to favor collecting or cultivation, without something to tip people towards the labor investment in cultivation. The social importance of cereals, to support large seasonal gatherings and rituals (cf. Asouti and Fuller 2013), and perhaps competitive feasting (cf. Hayden 2009) or to support emerging craft specialists (Fuller and Qin 2010) could provide such a pull towards cultivation. The Near East and China can be contrasted in terms of the potential conflicts between seasonal availability of wild nuts and wild cereals, with these two directly in conflict for harvest period in the Yangtze Valley, and thus climate driven declines in woodland acorn sources may have subtly pushed people towards more reliance on managing wetland margins and wild rice (Fuller and Qin 2010). Once started down the path of cultivation the ensuing unintentional development of the domestication syndrome would have made it harder and harder for people to withdraw form this entanglement. This pull would have been more difficult in the case of rice due to its wild perenniality problem (Figure 3 ).

In the cases of cultivation by mobile hunter-gatherers, the patchy availability of millets would have encouraged the creation of new patches so that they could be available, when needed for seasoned social events or as fall-back foods for people and their domestic fauna (e.g. dogs). In the case of North China, environmental factors like the Early Holocene expansion of woodlands could have pushed people towards more pig hunting and pig-keeping, which favoured sedentism and more reliable sources of millets as pig feed (Figure 3). By contrast, in India it was the opening of more savannah (see Fuller 2011) with more limited dry season watering holes that might have encouraged the creation of pulse and millet gardens, and territoriality of these wetter locales. This in turn became entangled with larger groups gathered for harvests, feasts, and investment in creating communities, if only seasonally to start with.

In each of these cases, however, there were also unpredictable connections between humans and things, which must be considered in relation to the historical weight of pre-existing cultural traditions rather than determined by environmental context. This is particularly the case with how food plants were processed and transformed into cooked foods. As explored in Fuller and Rowlands (2011) there has been a long-term distinction between an East Eurasian focus on boiling and steaming and a West Eurasian focus on production of flours and breads. There is nothing inherent in the cereal species or human digestive needs that predicts this division, and archaeological evidence 
suggests the origins of this processing division reach back in to the Pleistocene, long-before $(\sim 10,000$ years before) crops were chosen for cultivation. However, once cultivation began these traditions of cooking became entwined with and elaborated in relation to early crop plants. Thus, boiled/steamed food in pots provided a context in which taste for sticky foods, like glutinous rice or millets, could evolve, requiring genetic mutation on the part of crops (Fuller and Rowlands 2011). By contrast, bread became a central symbol in metaphors of the Near East and derived agricultural traditions. For example, to have a "bun in the oven" as a metaphor for pregnancy was afforded by traditions of grinding and baking. As a growing part of people's lives, both in terms of work and sustenance- the very substance that maintains bodies, families and communities, food production, both agriculture and cooking, became embedded in ritual and symbolism.

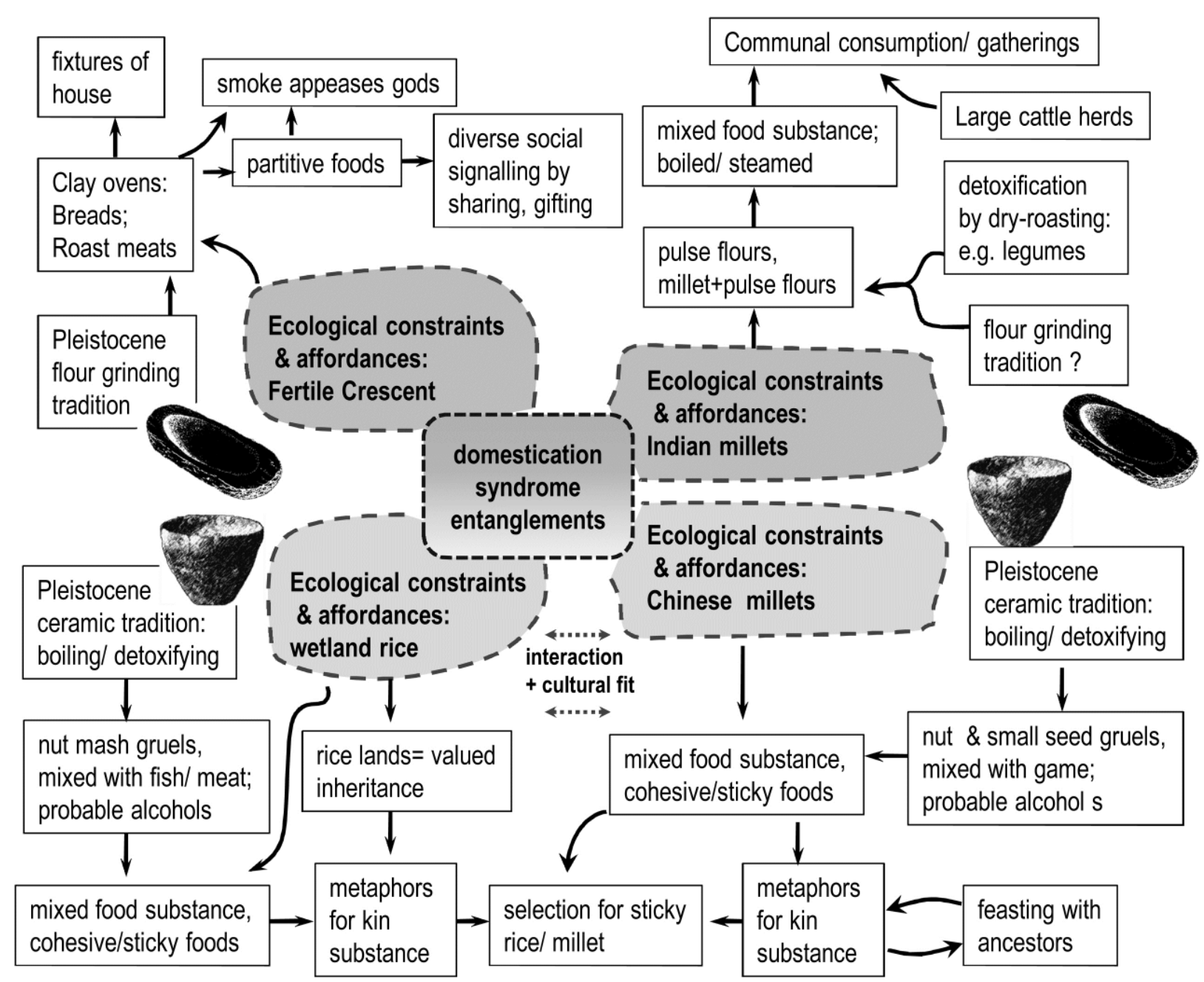

Figure 4: Food traditions entanglegram

We can suggest regional entanglements that were determined by pre-existing cultural history, contingent ideologies, and which set in place path dependencies in terms of cultural traditions (Figure 4). In the case of Western Asia in which cooking traditions focusing on heavy grinding stones and ovens, there was strong attachment to the house. Groundstones are rarely moved ethnographically (Wright 1994), while ovens are fixed. Fuller and Rowlands (2011) argued that these forms of cooking lent themselves to traditions of sacrifice in which distant gods were appeased by rising smoke, and roasted meats and baked breads became foci of sharing within and between houses and across communities, with differential access becoming indicative of social rank. Continuity was embodied in the houses themselves, and these were given investment to create permanence and continuity. The continuities of houses at Çatalhöyük have been characterized as representing a "house society" (Hodder 2012: 152), and in addition to being locales of crop storage, 
grinding and cooking, the dead were also cached here, and periodically parts of them, such as skulls, were retrieved for rituals beyond the house. The wider recurrence on skulls in ritual and cached in houses suggests an underlying metaphor of remembered traditions and cultural transmission in the Neolithic Near East (e.g. Kuijt 2008).

In Neolithic China, both in the rice and millet areas, the evidence of burial grounds suggests that the ancestors were more fixed. Graves are associated with ceramic vessel sets, which represented food and liquid (i.e. alcohol) offerings that were part of feasting meant to please ancestors and reinforce the continuities of lineages (e.g. Liu 2000; Nelson 2003). The longer-term tradition in China has been the veneration of ancestors, who are kept close to the family through food offerings, while the family shares foods to maintain the substance of kinship. This can be represented metaphorically in cooked foods that are steamed or boiled to be cohesive and sticky, and therefore fitting that it was in eastern Asia where literally sticky varieties of rice, millets and other cereals evolved through selected mutations in the waxy gene (Sakamoto 1996; Fuller and Rowlands 2011).

In Southern India we witness the pull of communal herd gathering and crop-processing towards creating appropriate locales for sedentism. Grinding tools were often fixed as bedrock mortars (and querns), tying crop processing to granite outcrops and hills (Fuller et al. 2001). In the wider landscape seasonal gatherings of cattle herds were memorialized through dung accumulations that were burnt in the same spots and developed over a few generations into substantial ash-mounds (Fuller et al. 2001; Boivin 2004; Johansen 2004). It is now clear that when more sedentary villages did develop they did so after, and literally overlying earlier ashmounds (Boivin et al. 2005: 70). We can consider the memorialized seasonal cattle fairs as consecrating ground for settlement, and where this co-occurred with bedrock crop-processing features, fixed agricultural communities were created. Thus, rather than ancestors or houses that were the links to past tradition, it was the physical memorial of past human and cattle gatherings that was the focus of communities, grain storage and feasting events. The centrality and cattle and cattle-products in symbolism has persisted since the Neolithic in this region.

The comparisons above suggest both parallelism in the coevolution between crops and cultural practices and areas of divergent entanglements. Parallelisms are to be found in the rigid path dependencies of the domestication syndrome (Figure 2), while regional and species-related ecologies added differing feedbacks and opportunities (Figure 3). The evolution of plant exploitation and cultivation was in turn enmeshed in longer-term regional traditions (Figure 4) that included cooking, acquired tastes and the metaphorical connections of these wider-world and belief systems.

\section{Acknowledgements}

Our Current research on Comparative Pathways to Agriculture, is supported by an European Research Council grant (ComPAg, no. 323842). Research on early rice cultivation by DQF, LQ was supported by a grant from UK NERC (NE/G005540/1), and a Chinese Education Ministry Grant (to QL).

\section{Bibliography}

Asouti, Eleni and Dorian Q. Fuller. "A Contextual Approach to the Emergence of Agriculture in Southwest Asia." Current Anthropology 54,no.3 (2013): 299-345.

Bakels, Corrie, C. The Western European loess belt; Agrarian history, 5300 BC - AD 1000. Dordrecht Heidelberg London New York: Springer, 2009.

Baskin, Carol, C., and Jerry M. Baskin. Seeds: Ecology, Biogeography, and Evolution of Dormancy and Germination. New York: Academic Press, 2001.

Barton, Huw and Tim Denham. "Vegeculture and Social Life in Island Southeast Asia" In Why Cultivate? Anthropological and Archaeological Approaches to Foraging-Farming Transitions in 
Southeast Asia, edited by Graham Barker and Monica Janowski, 17-25. Cambridge, UK: McDonald Institute for Archaeological Research: McDonald Institute Monographs, 2011.

Bettinger, Robert L., Loukas Barton, and Christopher Morgan. "The origins of food production in North China: a different kind of agricultural revolution." Evolutionary Anthropology 19 (2010): 921.

Boggard, Amy, Rebecca Fraser, Tim H. E. Heaton, Michael Wallace, Petra Vaiglova, Michael Charles, Glynis Jones, Richard P. Evershed, Amy K. Styring, Niels H. Andersen, Rose-Marie Arbogast, László Bartosiewicz, Armelle Gardeisen, Marie Kanstrup, Ursula Maier, Elena Marinova, Lazar Ninov, Marguerita Schäfer, and Elisabeth Stephan. "Crop manuring and intensive land management by Europe's first farmers." Proceedings of the National Academy of Sciences 110, no. 31(2013): 12589-12594.

Boivin, Nicole. "Landscape and Cosmology in the South Indian Neolithic: New Perspectives on the Deccan Ashmounds." Cambridge Archaeological Journal 14, issue2(October 2004): 235 257.

Boivin, Nicole, R. Korisettar, and Dorian Q. Fuller. "Further Research on the Southern Neolithic and the Ashmound Tradition: The Sanganakallu-Kupgal Archaeological Research Project Interim Report." Journal of Interdisciplinary Studies in History and Archaeology 2, no.1 (2005): 63-89.

Cohen, David Joel. "The Beginnings of Agriculture in China: A Multiregional View." Current Anthropology 52, no. S4 (2011): S273-S293.

Colosi, Joseph C., Paul B. Cavers, and Marguerite A. Bough. "Dormancy and survival in buried seeds of proso millet (Panicummiliaceum)." Canadian Journal of Botany 66 no.1 (1988): 161-168.

Danziger, Edmund J. The Chippewa of Lake Superior. Norman: University of Oklahoma Press, 1979.

De Wet, J. M. J. "Millets." In The Cambridge World History of Food, edited by Kenneth F. Kiple and KriemhildConeè Ornelas, 112-121. Cambridge: Cambridge University Press, 2000.

Doolittle, William, E. Cultivated landscapes of native North America. Oxford: Oxford University Press, 2000.

Douglas, Brian J., Thomas A. Gordon, Ian N. Morrison, and Murray G. Maw. "The biology of Canadian weeds. 70. Setariaviridis (L.). Beauv."Canadian Journal of Plant Science 65, no.3 (1985):669-690.

Doust, Andrew N. "Architectural evolution and its implications for domestication in grasses." Annals of Botany 100, no. 5 (2007): 941-50.

Elbaum, Rivka, Liron Zaltzman, Ingo Burgert, and Peter Fratzl. "The role of wheat awns in the seeddispersal unit." Science 316, no. 5826 (2007): 884-6.

Fuller, Dorian Q. "Contrasting Patterns in Crop Domestication and Domestication Rates: Recent Archaeobotanical Insights from the Old World." Annals of Botany 100, no.5 (October 2007): 903924.

Fuller, Dorian Q. "Finding Plant Domestication in the Indian Subcontinent." Current Anthropology 
Fuller, D., R. Korisettar and P. C. Venkatasubbaiah. "Southern Neolithic Cultivation Systems: A Reconsideration based on Archaeobotanical Evidence." South Asian Studies 17 (2001): 149-167.

Fuller, D. Q. and Emma L. Harvey. “The Archaeobotany of Indian Pulses: identification, processing and evidence for cultivation.” Environmental Archaeology11, no.2 (2006): 219-246.

Fuller, Dorian Q, Qin, Ling \& Harvey, Emma. "Evidence for a late onset of agriculture in the Lower Yangzi region and challenges for an archaeobotany of rice." In: Past Human Migrations in East Asia. Matching Archaeology, Linguistics and Genetics, edited by Alicia Sanchez-Mazas, Roger Blench, Malcolm D. Ross, Ilia Peiros, and Marie Lin, 40-83. London: Routledge, 2008.

Fuller, Dorian Q. and Robin G. Allaby. "Seed dispersal and crop domestication: shattering, germination and seasonality in evolution under cultivation." In Fruit Development and Seed Dispersal, Annual Plant Reviews Volume 38, edited by Lars Ostergaard, 238-295. Oxford: WileyBlackwell, 2009.

Fuller, Dorian Q. and Ling Qin. "Water management and labor in the origins and dispersal of Asian rice." World Archaeology 41, no. 1 (2009): 88-111.

Fuller, Dorian Q., Robin G. Allaby and Chris Stevens. "Domestication as innovation: the entanglement of techniques, technology and chance in the domestication of cereal crops." World Archaeology 42, no. 1 (2010): 13-28.

Fuller, Dorian Q. and Ling Qin. "Declining oaks, increasing artistry, and cultivating rice: the environmental and social context of the emergence of farming in the Lower Yangtze Region." Environmental Archaeology 15, no. 2 (2010): 139-15.

Fuller Dorian Q., Nicole Boivin, Tom Hoogervorst, and Robin Allaby. “Across the Indian Ocean: the prehistoric movement of plants and animals." Antiquity 85, no. 328 (2011): 544-558.

Fuller, Dorian Q. and Michael Rowlands. "Ingestion and Food Technologies: Maintaining differences over the long-term in West, South and East Asia." In Interweaving Worlds - systematic interactions in Eurasia, 7th to 1st millennia BC. Essays from a conference in memory of Professor Andrew Sherratt, edited by John Bennet, Susan Sherratt, and Toby C. Wilkinson, 37-60. Oxford: Oxbow Books Ltd, 2011.

Fuller, Dorian Q., Eleni Asouti, and Michael D. Purugganan. "Cultivation as slow evolutionary entanglement: comparative data on rate and sequence of domestication." Vegetation History and Archaeobotany 21, no. 2 (2012): 131-145.

Fuller, Dorian Q., Tim Denham, Manuel Arroyo-Kalin, Leilani Lucas, Chris Stevens, Ling Qin, Robin Allaby, and Michael D Purugganan. "Convergent Evolution and Parallelism in Plant Domestication Revealed by an Expanding Archaeological Record." Proceedings of the National Academy of Sciences, In press (2013).

Gu, Xing-You, Shahryar F. Kianian, Gary A. Hareland, Hoffer, Barry L., and Michael E. Foley. "Genetic analysis of adaptive syndromes interrelated with seed dormancy in weedy rice (Oryza sativa)." Theoretical and Applied Genetics 110 (2005): 1108-1118.

Harlan, Jack R., J.M.J De Wet, and E Glen Price. “Comparative evolution of cereals.” Evolution 27, 
Hayden, Brian. "The Proof is in the Pudding: Feasting and the Origins of Domestication." Current Anthropology 50 (2009):597-601.

Hodder, Ian. Entangled. An archaeology of the relationships between humans and things. Oxford: Wiley and Blackwell, 2012.

Hunt, Harriet V., Michael G. Campana, Matthews C. Lawes, Yong-Jin Park, Mim A. Bower, Christopher J. Howe, and Martin K. Jones. "Genetic diversity and phylogeography of broomcorn millet (Panicum miliaceum L.) across Eurasia.” Molecular Ecology 20, no. 22 (2011): 4756-4771.

Ishii, Takashige, Koji Numaguchi, Kotaro Miura, Kentaro Yoshida, Pham Thien Thanh, Than Myint Htun, Masanori Yamasaki, Norio Komeda, Takashi Matsumoto, Ryohei Terauchi, Ryo Ishikawa \& Motoyuki Ashikari. "OsLG1 regulates a closed panicle trait in domesticated rice." Nature Genetics 45 (2013): 462-465

Johansen, Peter G. "Landscape, Monumental Architecture and ritual: a reconsideration of the South Indian Ashmounds." Journal of the Anthropological Archaeology 23 (2004): 309-330.

Kluyver, Thomas, A., Michael Charles, Glynis Jones, Mark Rees and Colin P. Osborne. "Did greater burial depth increase the seed size of domesticated legumes?" Journal of Experimental Botany 64, issue 3 (2013): 4101-4108.

Kuijt, Ian."The Regeneration of Life. Neolithic Structures of Symbolic Remembering and Forgetting." Current Anthropology 49, no. 2 (2008): 171-197.

Li, Hui-Lin. "The origin of cultivated plants in southeast Asia.” Economic Botany 24 (1970): 3-19.

Liu, Li 2000. Ancestor worship: an archaeological investigation of ritual activities in Neolithic North China. Journal of East Asian Archaeology 2:129-164.

Lu, Tracey Lie-Dan. "A Green Foxtail (Setaria viridis) Cultivation Experiment in the Middle Yellow River Valley and Some Related Issues." Asian Perspectives 41, no. 1 (2002): 1-14.

Lu, Houyuan, Jianping Zhang, Kam-biu Liu, Naiqin Wu, Yumei Li, Kunshu Zhou, Maolin Ye, Tianyu Zhang, Haijiang Zhang, Xiaoyan Yang, Licheng Shen, Deke Xu, and Quan Li. "Earliest domestication of common millet (Panicum miliaceum) in East Asia extended to 10,000 years ago." Proceedings of the National Academy of Sciences of the United States of America 106, no.18 (2009): 7367-7372.

Lyon, Drew J. and David D Baltensperger. "Cropping systems control winter annual grass weeds in winter wheat." Journal of Production Agriculture 8 (1995): 535-539.

Manning, Katie, Ruth Pelling, Tom Higham, Jean-Luc Schwenninger, and Dorian Q. Fuller. "4500year old Domesticated Pearl Millet (Pennisetum glaucum) from the Tilemsi Valley, Mali: new insights into an alternative cereal domestication pathway in Africa". Journal of Archaeological Science 38, no. 2 (2011): 312-322.

Marshall, F. and Hildebrand, E. 2002. "Cattle before crops: the beginnings of food production in Africa."Journal of World Prehistory16: 99-143. 
Matz, Samuel A. "Millet, wild rice, adlay, and rice grass." Cereal Science, 225-229. Westport, CT: AviPress, 1986.

Meiko, Eda, Ayumi Izumitani, Katsuyuki Ichitani, Makoto Kawase, and Kenji Fukunaga. "Geographical variation of foxtail millet, Setaria italica (L.) P. Beauv. based on rDNA PCR-RFLP." Genetic Resources and Crop Evolution 60 (2013): 265-274.

Moles, Angela T., David D. Ackerly, John C. Tweddle, John B. Dickie, Roger Smith, Michelle R. Leishman, Margaret M. Mayfield, Andy Pitman, Jeff T. Wood, and Mark Westoby. "Global patterns in seed size." Global Ecology and Biogeography 16 (2007): 109-116.

Nelson, Sarah Milledge. "Feasting the Ancestors in Early China." In The Archaeology and Politics of Food and Feasting in Early States and Empires, edited by Tamara L. Bray, pp. 65-89. New York: Kluwer/Plenum, 2003

Nesbitt, Mark. "Grains" In Cultural History of Plants, edited by Sir Ghillean Prance and Mark Nesbitt, 45-60. London: Routledge, 2005.

Qin, Ling. "Archaeobotanical research and expectations on Chinese argicultural origins." In School of Archaeology and Museology of Peking University, Center of the Study of Chinese Archaeology. Peking University, 260-315. Beijing: Cultural Relics Press, 2012.

Reynolds, Peter J."Experimental Iron Age storage pits: an interim report" Proceedings of the Prehistoric Society 40 (1974): 118-31.

Sakamoto, Sadao. "Glutinous-endosperm starch food culture specific to Eastern and Southeastern Asia. In Redefining Nature. Ecology, Culture and Domestication, edited by Roy Ellen and Katsuyoshi Fukui, 215-231. Oxford: Berg, 1996.

Sherratt, Andrew. "Climatic cycles and behavioural revolutions: the emergence of modern humans and the beginning of farming."Antiquity71 (1997): 271-287.

Song, Jixiang, Zhao Zhijun and Dorian Q. Fuller. "The archaeobotanical significance of immature millet grains: an experimental case study of Chinese millet crop processing." Vegetation History and Archaeobotany 22, no. 2 (2013): 141-152.

Tanno, Ken-ichi and George Willcox. "Distinguishing wild and domestic wheat and barley spikelets from early Holocene sites in the Near East." Vegetation History and Archaeobotany 21, no. 2 (2012): 107-115.

Toussaint-Samat, Maguelonne. A History of Food. Trans. by Anthea Bell. Cambridge, M.A: Blackwell Reference, 2009.

Vaughan, Duncan Alexander, Bao-Rong Lu, and Norihiko Tomooka. "The evolving story of rice evolution." Plant Science 174, no. 4 (2008): 394-408.

Vennum, Thomas. Wild rice and the Ojibway people. St. Paul, Minnesota: Minnesota Historical Society Press, 1988.

Wang, Chi-Wu. The Forests of China with a survey of Grassland and Desert Vegetation. Cambridge, Mass.: Maria Moors Cabot Foundation, Harvard University, 1961. 
Willcox, George. "Searching for the origins of arable weeds in the Near East." Vegetation History and Archaeobotany 21, no. 2 (2012): 163-167.

Wright, Karen. "Ground stone tools and hunter-gatherer subsistence in southwest Asia: implications for the transition to farming."American Antiquity 59, no.2 (1994): 238-263.

Yang,Xiaoyan,Huw J. Barton,Zhiwei Wan,Quan Li,Zhikun Ma, Mingqi Li,Dan Zhang, and Jun Wei. "Sago-Type Palms Were an Important Plant Food Prior to Rice in Southern Subtropical China." PLoS ONE 8, no.5 (2013): e63148.

Zohary, Daniel. "The progenitors of wheat and barley in relation to domestication and agricultural dispersal in the Old World". In The Domestication and Exploitation of Plants and Animals, edited by Peter Ucko and Geoff Dimbleby, 47-66. London: Duckworth, 1969.

Zohary, Daniel, Maria Hopf, and Ehud Weiss. Domestication of plants in the Old World. $4^{\text {rd }}$ Edition. New York and Oxford: Oxford University Press, 2012. 